\title{
Normality Proper to the Time is Sickness
}

Fabian Freyenhagen

Krisis 41 (2): 87-88.

DOI

10.21827/krisis. 41.2 .38248

\section{Licence}

This work is licensed under a Creative Commons Attribution 4.0 License International License (CC BY 4.0). (C) 2021 The author(s). 


\section{Normality Proper to the Time is Sickness}

Fabian Freyenhagen

Capitalist societies have the uncanny ability to constantly change, and yet remain the same.

An envisaged psychoanalysis of the prototypical culture of mid-twentieth-century society - especially as it presented itself in California - was predicted to reveal that sickness proper to this time is normality $(\mathbb{S} 36)$. Being a regular guy or popular girl then required blocking all signs of illness, displaying exuberant vitality and cheerfulness as if one's soul's salvation depended on it. In fact, the mechanical nature of the bodily comportment and the suppression of even as much as a furrowed brow inadvertently suggested that the hearts had stopped beating long ago; and that what was presented to us were corpses, skilfully prepared so as to not scare off anyone at the open-casket funerals that were hidden in plain sight. It was a time when being homosexual was considered a mental illness, which tells us not only about the sexual mores then, but also about the stigma - even taboo - that was attached to those not considered normal in their mental or emotional make-up.

As times have changed, so have mores. Being diagnosed as presenting with mental illness has become much less stigmatised, especially if the sufferers are privileged and do not have socially unacceptable delusions. Certain conditions are now often understood as examples of neurodiversity, rather than abnormality. Being neurologically different is sometimes even celebrated, as in the trope of the troubled geniuses of the world of art, mathematics, or finance that populate the silver screen and on-demand streaming devices. It has become statistically likely and accepted - even fashionable, judging by how many princes and other celebrities go public with it - to receive at least one diagnosis in one's lifetime, be it anxiety, depression, attention deficit hyperactivity, or autistic spectrum. It is seen as a mark of individuality to be an instance of a general category, although this absurdity is partly masked by the exceptions and reasonable adjustments an acknowledged diagnosis might make available to whoever is prepared to accept it (this quid pro quo can be witnessed in university contexts, where the rise in mental health problems has been particularly striking). Still, perhaps, so far so good. Things become more troubling when we consider the open secret that an ever-increasing number of us are prescribed and take medication meant to address low mood or anxiety, conceptualised as chemical imbalances in the brain; and the less open secret that the side-effects might be worse than the (purported) disease. The shift from the "age of anxiety" to the "age of depression" has been accompanied by a shift of response, from one of telling people to man up or be locked up to one of popping pills and exemption badges. What it means to be mentally distressed has changed in a way that can almost be dated to a specific year: in 1980 a watershed occurred in psychiatry - inevitably first in the USA - whereby mental distress became understood as a bundle of symptoms, for which the aetiology need not be known. The individualisation of mental distress - something that already worried Adorno about mid-twentieth-century psychoanalysis's becoming part of social hygiene - thereby reached a completely new level. The change in ontology within psychiatry made this distress into an illness of the brain of yet-unknown origin. The causal nexus of these developments is like a vortex 
of forces that cannot be easily disentangled. Yes, there have been changes in cultural and moral - including sexual - norms, but the result we are faced with today also owes much to the material forces brought to bear by the pharmaceutical companies and the incentives structures of private and public health-care providers. Destigmatisation, in our times, has come at the expense of commodification. If only the suffering wouldn't so stubbornly persist through its normalisation and medicalisation! For while it is a source of income, it is also a source of inconvenience for the new enterprenerial world.

Plus ça change, plus c'est la même chose. Whether to be normal is to deny illness to the point of being dead, or to accept illness to the point of dying of the supposed cure, does not alter in the slightest the aetiology of the individual and social malaise, or indeed the lack of a real cure. Once again, bringing to light - be it the mid-twentiethcentury hygiene of social adaptability or the early twenty-first century explosion of mental illness diagnosis - does not automatically remove but instead can hide, indeed has hidden, the "secret domain of the faeces" $(\mathbb{S} 36)$, the remaining wretchedness; and more effectively so. The signs of repression are perhaps no longer repressed at the individual level, but now at the collective one. Yes, there is increasing recognition that there are social causes of illness, including mental distress. But even this insight is co-opted into social control, albeit often in the supposedly innocent and subtle form of changing the "choice architecture" advocated by behavioural insight teams. Instead of social change, we get mindfulness and resilience training; and whether the default becomes 'opt out' instead of 'opt in', will not change this.

When the norm has become for society to be ill, what's the future for health? Perhaps there is hope in the thought that no normalising of suffering can completely erase the critical potential suffering has as motor of thinking.

\section{Biography}

Fabian Freyenhagen is Professor of Philosophy at the University of Essex, UK. His publications include Adorno's Practical Philosophy: Living Less Wrongly (Cambridge University Press, 2013) and articles and book chapters on Critical Theory. He is investigating the idea of social pathology, particularly in relation to mental distress, its conceptualisations and social causes. 